\title{
CONF-9606/10--2
}

Note: This is a preprint of a paper being submitted for publication. Contents of this paper should not be quoted nor referred to without permission of the author(s).

Paper for proceedings of the International Conference on Ion Implantation Technology Austin, Texas (June 17-21, 1996)

\section{Effects of Ion Beam Mixing on the Formation of SiGe Nanocrystals by Ion Implantation}

J. G. Zhu, C. W. White, J. D. Budai, and S. P. Withrow

Oak Ridge National Laboratory

Oak Ridge, TN

D. O. Henderson

Fisk University

Nashville, TN

\begin{abstract}
"The submitted manuscript has been authored by a contractor of the U.S. Government under contract No. DE-ACO5960R22464. Accordingly, the U.S Government retains a nonexclusive, royalty-free license to publish or conse form reproduce the published form of this contribution, or allow others to do so, for U.S. Government purposes."
\end{abstract}

Prepared by the Oak Ridge National Laboratory

Oak Ridge, Tennessee 37831

managed by

LOCKHEED MARTIN ENERGY RESEARCH CORP.

for the

U.S. DEPARTMENT OF ENERGY

under contract DE-AC05-96OR22464

June 1996 


\section{DISCLAIMER}

This report was prepared as an account of work sponsored by an agency of the United States Government. Neither the United States Government nor any agency thereof, nor any of their employees, makes any warranty, express or implied, or assumes any legal liability or responsibility for the accuracy, completeness, or usefulness of any information, apparatus, product, or process disclosed, or represents that its use would not infringe privately owned rights. Reference herein to any specific commercial product, process, or service by trade name, trademark, manufacturer, or otherwise does not necessarily constitute or imply its endorsement, recommendation, or favoring by the United States Government or any agency thereof. The views and opinions of authors expressed herein do not necessarily state or reflect those of the United States Government or any agency thereof. 


\section{DISCLAIMER}

Portions of this document may be illegible in electronic image products. Images are produced from the best available original document. 



\title{
Effects of Ion Beam Mixing on the Formation of SiGe Nanocrystals by Ion Implantation"
}

\author{
Jane G. Zhu, C. W. White, J. D. Budai, and S. P. Withrow \\ Oak Ridge National Laboratory, Solid State Division \\ Oak Ridge, TN 37831-6057, USA \\ D. O. Henderson \\ Fisk University, Physics Department \\ Nashville, TN 37208, USA
}

\begin{abstract}
Nanocrystals of SiGe alloy have been formed inside a $\mathrm{SiO}_{2}$ matrix by the ion implantation technique. It is demonstrated that the sequence of implantation of $\mathrm{Si}$ and $\mathrm{Ge}$ ions affects the nanocrystal formation significantly. This is explained by the ion-beam mixing effect during sequential implantation. The size distributions of the SiGe nanocrystals can also be controlled by annealing conditions.
\end{abstract}

\section{INTRODUCTION}

Semiconductor nanocrystals, exhibiting new electronic and optical properties, are attractive materials due to their potential applications in optoelectronics. The ion implantation technique has been used to synthesize nanocrystals of a variety of semiconductor materials, such as $\mathrm{Si}, \mathrm{Ge}, \mathrm{III}-\mathrm{V}$ and II-VI semiconductors [1-11]. Our studies on the elemental and compound semiconductor nanocrystals show that the size distribution of these nanocrystals can be controlled by the implantation dose and thermal annealing temperature. To form nanocrystals of alloy semiconductors, it requires that two different elements to be implanted inside the host matrix. This paper presents our study of SiGe nanocrystals formed in $\mathrm{SiO}_{2}$ by the ion implantation technique. For materials consisting of more than one element, the sequence of implantation for each constituent species becomes an important issue [12].

\section{EXPERIMENTAL}

$\mathrm{SiGe}$ semiconductor nanocrystals were formed by implantation of $\mathrm{Si}$ and Ge ions into a $\mathrm{SiO}_{2}$ layer on (100) silicon and subsequent thermal annealing. A typical $\mathrm{SiO}_{2}$ layer was $\sim 0.75 \mu \mathrm{m}$ thick, formed by thermally oxidizing a (100) Si wafer. The samples used in this paper were heavily implanted with equal doses, $3 \times 10^{17} \mathrm{~cm}^{-2}$, of $\mathrm{Si}$ and $\mathrm{Ge}$ at room temperature (RT), unless specified otherwise. The implant energies, $215 \mathrm{keV}$ for $\mathrm{Si}$ and $500 \mathrm{keV}$ for $\mathrm{Ge}$, were chosen to overlap the peak concentrations in the middle of the oxide layer. Samples were annealed isochronally for $1 \mathrm{~h}$ under $\mathrm{Ar}+4 \% \mathrm{H}_{2}$ ambient at atmospheric pressure. The annealing temperatures varied from $900^{\circ} \mathrm{C}$ to $1100^{\circ} \mathrm{C}$.

The nanocrystalline structures were investigated by transmission electron microscopy (TEM) and $\mathrm{X}$-ray diffraction. All the TEM specimens were prepared in cross sections since the concentration distribution from ion implantation is a function of depth. Depth profiles of implanted $\mathrm{Ge}$ ions were examined by Rutherford backscattering spectrometry (RBS) using a $2.3 \mathrm{MeV} \mathrm{He}{ }^{2+}$ beam.

\section{RESULTS AND DISCUSSIONS}

A cross-sectional TEM image, from a sample implanted with $\mathrm{Ge}$ at $\mathrm{RT}$ and $\mathrm{Si}$ at $500^{\circ} \mathrm{C}$ and then annealed at $1000^{\circ} \mathrm{C}$ for $1 \mathrm{~h}$, is shown in Fig. 1. A high density of SiGe particles precipitates during annealing for this high dose sample. Similar to the Ge nanocrystals [5], these SiGe nanocrystals are randomly oriented and near-spherical in shape in the amorphous $\mathrm{SiO}_{2}$ matrix. The sizes of the $\mathrm{SiGe}$ nanocrystals are in the range of $2-20 \mathrm{~nm}$. The X-ray diffraction measurement, shown in Fig. 1, confirms the formation of SiGe alloy.

When the sample, implanted with $\mathrm{Ge}$ and then $\mathrm{Si}$, was annealed at $1100^{\circ} \mathrm{C}$ that is near to the melting temperature of the $\mathrm{SiGe}$ alloy, the SiGe precipitates grow to much larger sizes. Fig. 2 shows that the large precipitates extend up to a

\footnotetext{
- Oak Ridge National Laboratory is managed by Lockheed Martin Energy Research Corp. for the U.S. Deparment of Energy under contract number DE-AC05-960R22464. Research at Fisk University is sponsored by Department of Energy under contract number DE-FG05-94ER45521.
} 
few tens of nanometers in size. In the middle of the implanted region, where the concentration is the highest, it appears that coalescence of the particles has occurred. In this region, the SiGe precipitates are usually not spherical in shape. A highresolution TEM image in Fig. 3 shows a precipitate with faceted surfaces/interfaces, mostly $\{111\}$ and $\{100\}$ lattice planes. When the sequence of implantation of $\mathrm{Si}$ and $\mathrm{Ge}$ is reversed, the precipitates of $\mathrm{SiGe}$ alloy are much bigger after annealing under the same condition, as shown in Fig. 4 . The
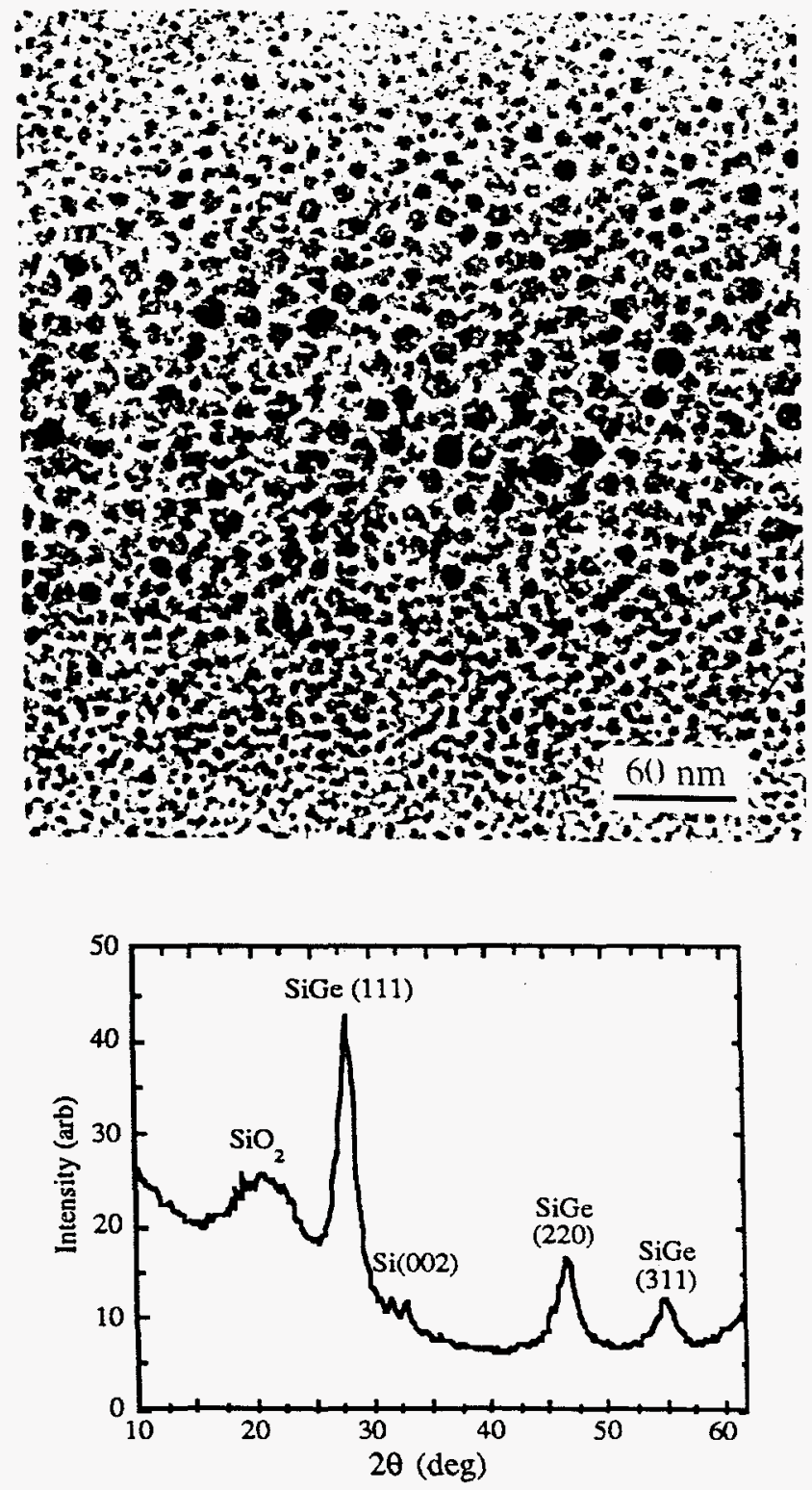

Fig. 1. Cross-sectional TEM image and X-ray diffraction spectrum from a sample implanted with $\mathrm{Ge}$ (RT) and $\mathrm{Si}\left(500^{\circ} \mathrm{C}\right)$ and annealed at $1000^{\circ} \mathrm{C} / 1 \mathrm{~h}$.

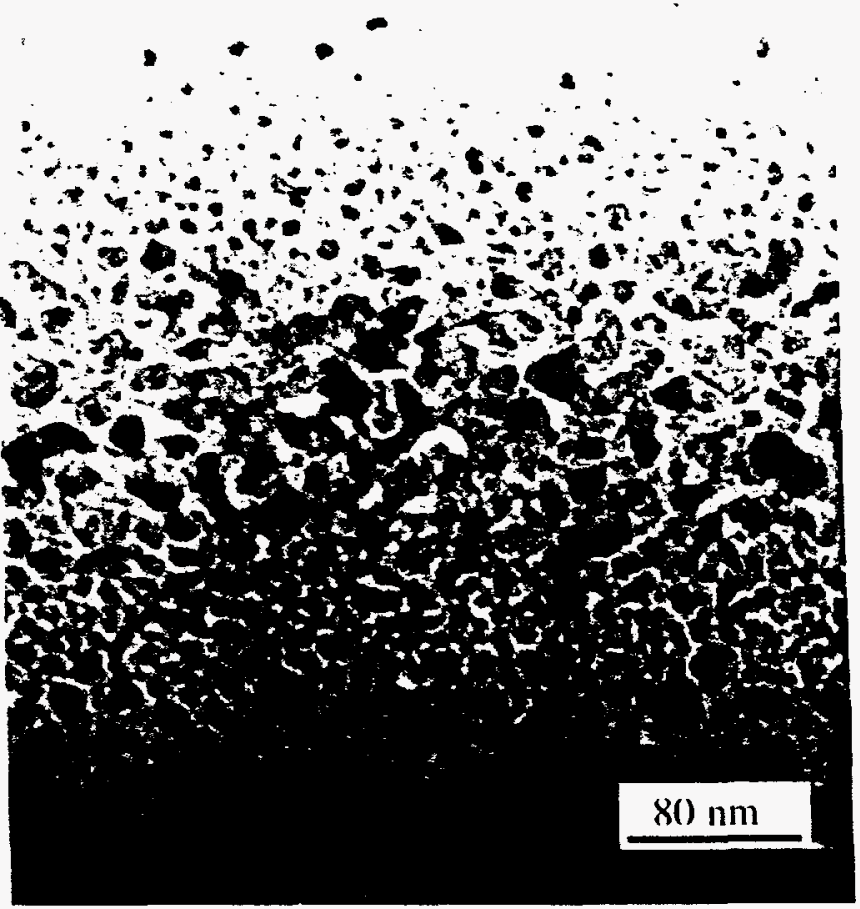

Fig. 2. Cross-sectional TEM image of a sample implanted with $\mathrm{Ge}$ and $\mathrm{Si}$ and annealed at $1100^{\circ} \mathrm{C}$.

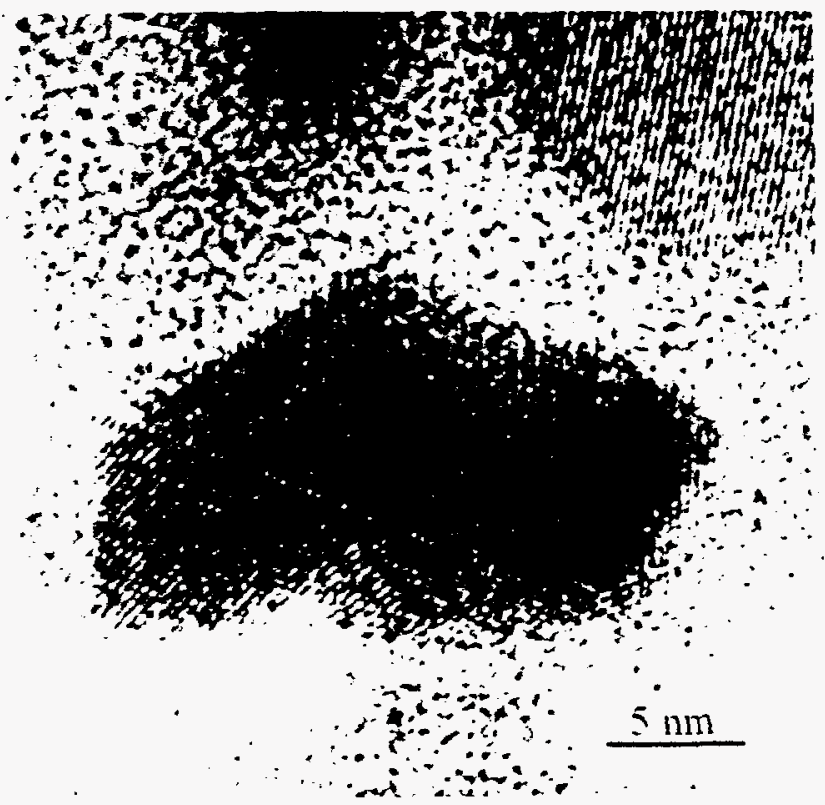

Fig. 3. A high-resolution TEM image showing a faceted precipitate. 
large precipitates are about a few hundreds of nanometers. Coarsening of SiGe particles is much more significant in this sample implanted with Si first and then Ge.

RBS measurements have been used to obtain $G e$ concentration-depth profiles. Fig. 5 shows the Ge profiles for two pairs of samples, one implanted with Ge first and then $\mathrm{Si}$ and the other implanted with Si first and then $\mathrm{Ge}$, before and after annealing at $1100^{\circ} \mathrm{C}$. At the as-implanted stage, the Ge profile for the sample implanted with $\mathrm{Ge}$ first is broader than that for the sample implanted with Si first. The broadening of the Ge profile can be explained by the ion-beam mixing effect which occurs when $\mathrm{Si}$ ions are implanted after the $\mathrm{Ge}$ implantation. After annealing at $1100^{\circ} \mathrm{C}$, sharpening of the Ge peak is very prominent for the sample implanted with $\mathrm{Si}$ first. There is also some sharpening of the Ge profile for the sample implanted with Ge first. These RBS results are consistent with the TEM observation that the SiGe precipitates are much bigger in the sample implanted with $\mathrm{Si}$ first after annealing at $1100^{\circ} \mathrm{C}$. X-ray diffraction peak width measurements also shows larger precipitate sizes in samples where $\mathrm{Si}$ is implanted before $\mathrm{Ge}$. The concentration of the SiGe alloy precipitated would vary from the targeted $\mathrm{Si}_{0.5} \mathrm{Ge}_{0.5}$ with different $\mathrm{Ge}$ concentration profiles. The center region in the sample implanted with Si first is more likely to

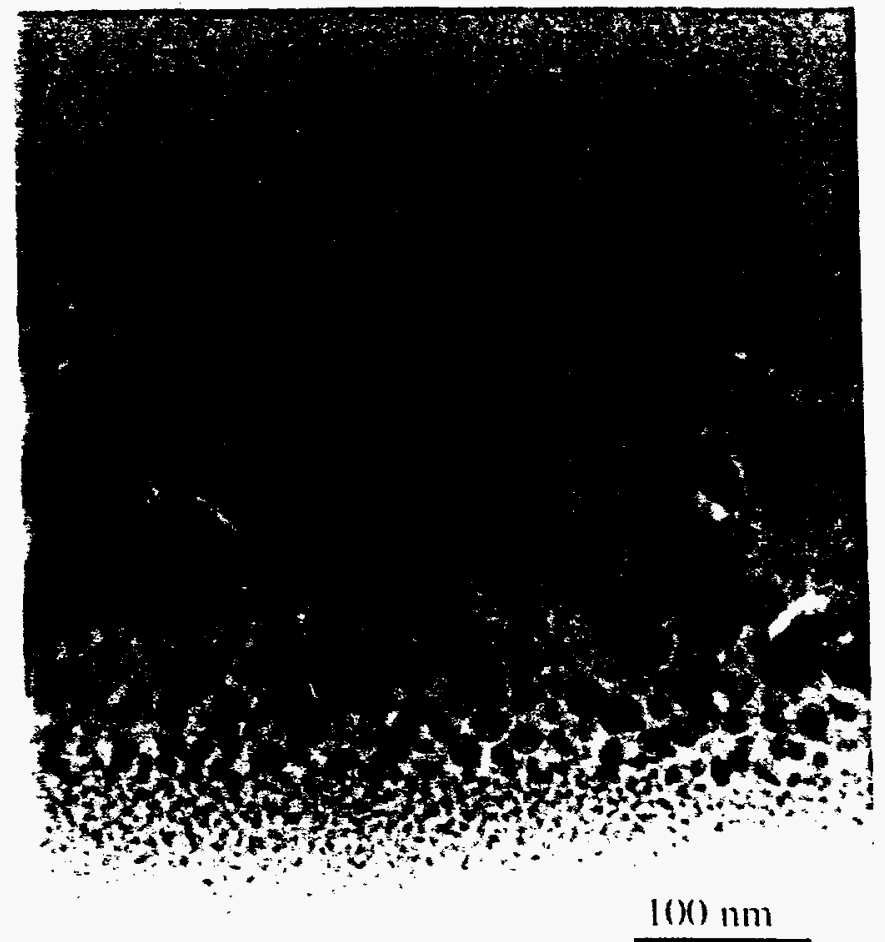

Fig. 4. Cross-sectional TEM image of a sample implanted with $\mathrm{Si}$ and $\mathrm{Ge}$ and annealed at $1100^{\circ} \mathrm{C}$. be Ge rich, and thus the alloy would have a lower melting point. This helps to explain why the SiGe precipitates in the center of the implanted region, which is Ge-rich for the sample implanted with Si first, are much bigger than those in the sample implanted with $\mathrm{Ge}$ first. Our previous study has revealed that $\mathrm{Ge}$ nanocrystals can grow much bigger in $\mathrm{SiO}_{2}$ matrix than Si nanocrystals under similar thermal annealing conditions [5]. In the upper and lower regions in the sample implanted with Ge first (see Fig. 2), the SiGe precipitates are Ge rich (since the center region is Si rich) with near spherical shape. The particies in the upper and lower regions in the sample implanted with Si first (see Fig. 4) are considered to be Si rich and are much smaller in size.

Small SiGe nanocrystals can be formed when the sample is annealed at lower temperatures. Fig. 6 shows a cross-
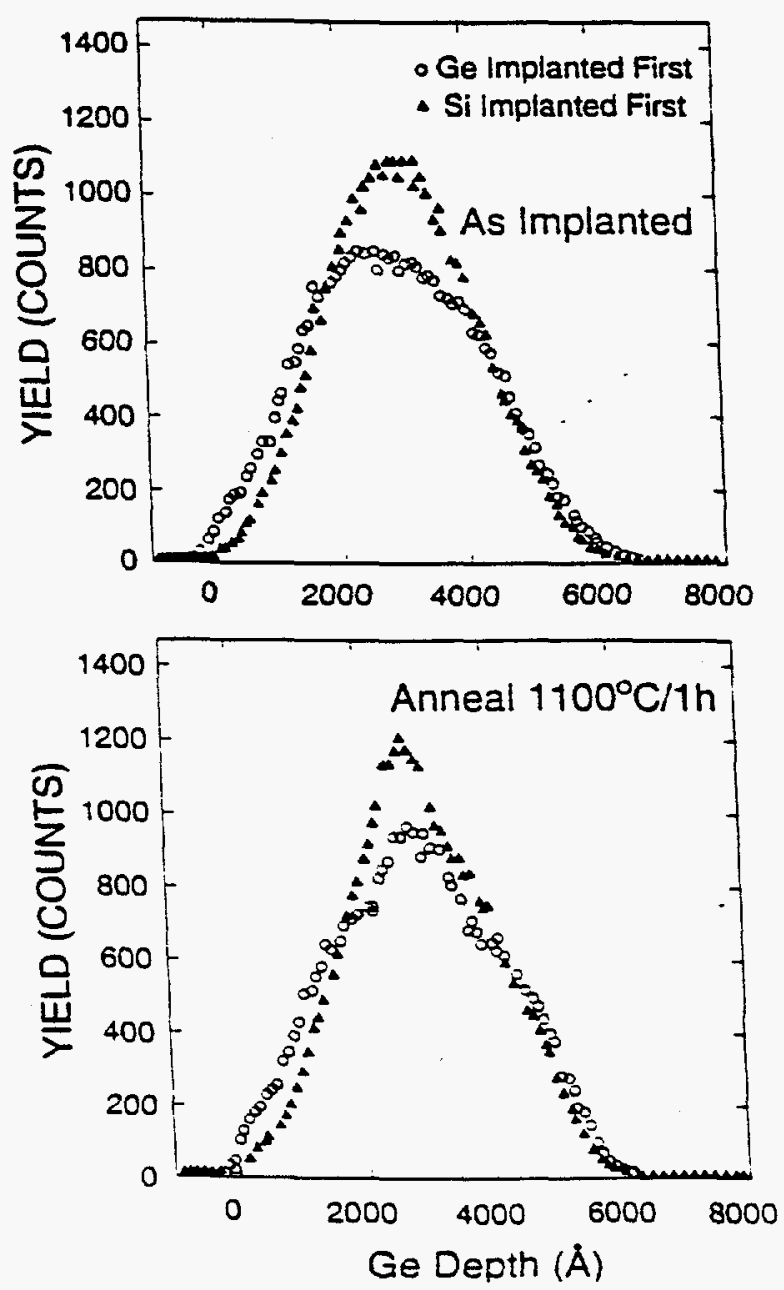

Fig. 5. Ge concentration-depth profiles measured by RBS from samples implanted with $\mathrm{Si}$ and $\mathrm{Ge}$ with different implantation sequences in the as implanted stage and after annealing at $1100^{\circ} \mathrm{C}$. 


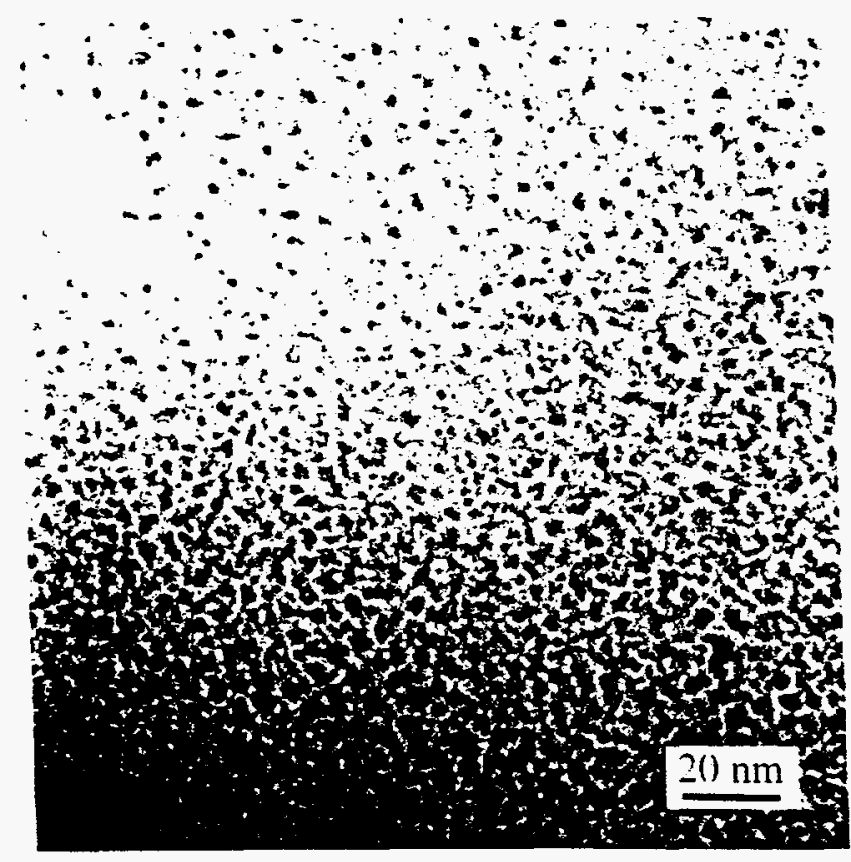

Fig. 6. Cross-sectional TEM image of a sample implanted with $\mathrm{Ge}$ and $\mathrm{Si}$ and annealed at $900^{\circ} \mathrm{C}$.

sectional TEM image from a sample implanted with $\mathrm{Ge}$ and $\mathrm{Si}$ and annealed at $900^{\circ} \mathrm{C}$ for $1 \mathrm{~h}$. These SiGe nanocrystals are $\sim 2 \mathrm{~nm}$ in size, which is the size desired for strong quantum confinement effect [13].

The exact amounts of deviation from the targeted alloy composition for SiGe nanocrystals need to be further investigated. However, X-ray diffraction measurements from the samples containing large-size SiGe precipitates indicate that the precipitates are close to $\mathrm{Si}_{0.5} \mathrm{Ge}_{0.5}$. The samples studied in this paper have been implanted with $\mathrm{Ge}$ and $\mathrm{Si}$ at RT except that shown in Fig. 1. Further investigation of implantation at elevated temperatures is under progress. Nucleation of nanocrystals is expected when a sample is heated during ion implantation, which could change the concentration-profile redistribution, therefore, assist the control of alloy concentration. Remarkable differences in the nanocrystal formation due to the change of implantation sequences have also been observed in the formation of GaAs nanocrystals. Details about the formation of GaAs nanocrystals can be found in [12], where the very different diffusion behaviors of $\mathrm{Ga}$ and $\mathrm{As}$ inside $\mathrm{SiO}_{2}$ have been illustrated.

\section{CONCLUSIONS}

Nanocrystals of SiGe alloy have been formed inside $\mathrm{SiO}_{2}$ matrices by the sequential ion implantation technique. The implantation sequence of $\mathrm{Si}$ and $\mathrm{Ge}$ ions is demonstrated to affect the nanocrystal formation substantially. The microstructure of these SiGe nanocrystals has been studied by TEM and X-ray diffraction. RBS measurements of the Ge concentration-depth profiles reveal the broadening of $\mathrm{Ce}$ profiles when $\mathrm{Si}$ ions are implanted after the $\mathrm{Ge}$ implantation due to the ion-beam mixing effect. This effect could alter the alloy composition when the implantation sequence is reversed. When the heavily implanted samples were annealed at a temperature about the melting temperature of the alloy, the sizes of the largest SiGe precipitates formed are about a few hundreds of nanometers in the sample implanted with $\mathrm{Si}$ first, about a few tens of nanometers in the sample implanted with $\mathrm{Ge}$ first. Very small SiGe nanocrystals, $\sim 2 \mathrm{~nm}$, are formed in the sample annealed at $900^{\circ} \mathrm{C}$. Results regarding the effect of implantation sequence on the formation of GaAs nanocrystals can be found elsewhere [12].

\section{REFERENCES}

[1] H. A. Atwater, K. V. Shcheglov, S. S. Wong, K. J. Vahala, R. C. Flagan, M. L. Brongersma, and A. Polman, "Ion beam synthesis of luminescent $\mathrm{Si}$ and Ge nanocrystals in a silicon dioxide matrix," Mat. Res. Soc. Symp. Proc. 316, 409 (1994).

[2] T. Shimizn-Iwayama, K. Fujita, S. Nakao, K. Saitoh, T. Fujita, and N. Itch, "Visible phoroluminescence in $\mathrm{Si}^{+}$-implanted silica glass," J. Appl. Phys. 75, 7779 (1994).

[3] C. W. White, J. D. Budai, J. G. Zhu, S. P. Withrow, R. A. Zuhr, Y. Chen, , D. H. Hembree, R. H. Magruder, and D. O. Henderson, "Compound semiconductor nanocrystais formed by seguential ion implantation," Mat. Res. Soc. Symp. Proc. 358, 169 (1995).

[4] J. G. Zhu, C. W. White, J. D. Budai, S. P. Withrow, and Y. Chen, "Semiconductor nanocrystals formed in $\mathrm{SiO}_{2}$ by ion implantation," Mat Res. Soc. Symp. Proc. 358, 175 (1995)

[5] J. G. Zhu, C. W. White, J. D. Budai, S. P. Withrow, and Y. Chen, "Growth of $\mathrm{Ge}, \mathrm{Si}$ and SiGe nanocrystals in $\mathrm{SiO}_{2}$ matrices," J. Appl. Phys. 78, 4386 (1995).

[6] C. W. White, J. D. Budai, J. G. Zhu, S. P. Withrow, D. H. Hembree, D. O. Henderson, A. Ueda, Y. S. Tung, R. Mu, and R. H. Magnder, "GaAs nanocrystals formed by sequential ion implantation," J. Appl. Phys. 79.1876 (1996).

[7] K. S. Min, K. Y. Scheglov, C. M. Yang, H. A. Atwater, M. L. Brongersma, and A. Polman. "The role of quantum-confined excitons vs defects in the visible luminescence of $\mathrm{SiO} 2$ films containing $\mathrm{Gc}$ nanocrystals," Appl. Phys. Lett. 68, 2511 (1996).

[8] S. Yu. Shiryaev, A. N. Larsen, and M. Deicher, "The chemical interaction between high-concentration, mixed-ion-implanted groupIII and -V impurities in silicon," " J. Appl. Phys. 72, 410 (1992).

[9] S. Yu. Shiryaev and A. N. Larsen, "High-dose mixed Ga/As and Ga/P ion implantations in silicon single crystals," Nucl. Instr. and Meth. B80/81, 846 (1993).

[10] C. W. White, J. D. Budai, J. G. Zhu, S. P. Withrow, and M. J. Aziz, "Ion-beam symthesis and stability of GaAs nanocrystals in silicon," Appl. Phys. Lett. 68, 2389 (1996).

[11] A. K. Rai, R. S. Bhattacharya, and S. C. Kung, "Fommation of TiN phase in $\mathrm{SiO}_{2}$ and $\mathrm{Si}$ through ion implantation of constituent elements." Mater. Letr. 13, 35 (1992).

[12] J. G. Zhu, C. W. White, D. J. Wallis, J. D. Budai, and S. P. Withrow, and D. O. Henderson, "Synthesis and properties of GaAs nanocrystals formed in $\mathrm{SiO}_{2}$ by ion implantation," Mat. Res. Soc. Symp. Proc. 396, 477 (1996).

[13] T. Takagahara and K. Takeda, "Theory of the quantum confinement effect on excitons in quantum dots of indirect-gap materials," Phys. Rev. B 46, 15578 (1992). 